\title{
(Re-)designing higher education curricula in times of systemic dysfunction: a responsible research and innovation perspective
}

\author{
Valentina C. Tassone ${ }^{1}$ - Catherine O'Mahony ${ }^{2}$. \\ Emma McKenna ${ }^{3} \cdot$ Hansje J. Eppink $^{1}$. \\ Arjen E. J. Wals ${ }^{1}$
}

Published online: 16 November 2017

(C) The Author(s) 2017. This article is an open access publication

\begin{abstract}
There is an urgent need to address the grand sustainability challenges of our time, and to explore new and more responsible ways of operating, researching, and innovating that enable society to respond to these challenges. The emergent Responsible Research and Innovation (RRI) policy agenda can act as a catalyst towards the development of new and more responsible research and innovation efforts. Inevitably, higher education needs to be closely attuned to this need and agenda, by preparing students to engage in RRI efforts. This paper makes a first step towards guiding the embedding of RRI within higher education. It does so by bringing together academic knowledge with phronesis or practical knowledge about what should be done in an ethical, political, and practical sense. It draws on a literature review and on the reflective practices of partners in the European Commission funded project EnRRICH (Enhancing Responsible Research and Innovation through Curricula in Higher Education), as well as on interviews and case studies gathered as part of the project. The paper suggests elements, especially design principles and a competence framework, for (re)designing curricula and pedagogies to equip higher education students to be and to become responsible actors, researchers, and innovators in a complex world, and to address grand sustainability challenges. In addition, this paper proposes that contemporary higher education teaching and learning policies and strategies, especially those promoting neoliberal agendas and marketized practices, need to adopt a more responsible and responsive ethos to foster the renewal of higher education in times of systemic dysfunction.
\end{abstract}

Valentina C. Tassone

valentina.tassone@wur.nl

1 Education and Learning Sciences Group, Wageningen University and Research, Wageningen, The Netherlands

2 Centre for the Integration of Research, Teaching and Learning, University College Cork, Cork, Ireland

3 Science Shop, Queen's University Belfast, Belfast, Northern Ireland 
Keywords Higher education · Responsible research and innovation - Grand sustainability challenges $\cdot$ Curricula $\cdot$ Competence

\section{Introduction}

We live in a turbulent age characterized by grand sustainability challenges - increasingly referred to as the Anthropocene (e.g., Gibson et al. 2015). According to scientists, it is a time when the functioning of the ecosystems and the well-being of people are at risk, and adequate responses are needed to address complex and ambiguous issues like climate change, resource scarcity, financial crisis, social injustice-just to mention a few (e.g., Crutzen 2002; Kates et al. 2001). Those global challenges represent persistent problems in our society. In order to respond to those challenges, scientists recommend exploring new pathways beyond the growth-based economic model driving our societies, and call for planetary stewardship and for a societal transition towards more responsible ways of relating to people and planet, and of operating, researching, and innovating (Brito and Stafford-Smith 2012; Steffen et al. 2011; the Royal Society 2012). Scientists emphasize, also, the need for a new contract between science and society which encourages greater connectivity between the academic community and the rest of society (e.g., Brito and Stafford-Smith 2012; Gibbons 1999). Inevitably, higher education (HE) needs to be closely attuned to this changing time, given its pivotal role in assisting students to navigate through the uncertain and "supercomplex" world we live in (Barnett 2000). However, as suggested by Sterling et al. (2013), there is a fundamental mismatch between the purposive and operational norms of $\mathrm{HE}$ as reflected and practiced by most higher education institutions (HEIs) in Europe and beyond, and the conditions of complexity, uncertainty, and unsustainability that we as a global society face, and that our graduates will inevitably encounter. It is argued that HE is at the crossroads, having to choose between the business as usual path of commodification of knowledge and learning focused on the well-being of the economy, or the innovative path of socio-ecological transition requiring new responsible forms of collaborative research and learning and alternative capabilities and values that contribute to the well-being of planet and people (e.g., Wals et al. 2016).

In parallel with this scientifically driven discussion, there is an emergent trend in the policy arena that points at the need for research and innovation (R\&I) efforts that responsibly address the grand challenges our society is currently facing (e.g., European Commission 2011). In Europe, this stems from a much longer standing policy drive towards bridging science and society (e.g., European Commission 2016). A "Science and Society" action plan was developed in 2001, followed by a "Science in Society" plan in 2007 under the 7th Framework Programme for Research and Technological Development. This has further evolved in 2010 to a "Science with and for Society" plan which makes Responsible Research and Innovation (RRI) a key policy area for European Research and a cross-cutting theme in Horizon 2020, which is the European Union's (EU) major research funding instrument. In this sense, RRI is the latest iteration of the EU's determination to bridge the gap between science and society, and to align R\&I outcomes with the needs and wants of 21st century society. An RRI approach encourages R\&I to be co-created from the outset among different societal actors (including researchers, policy makers, industry representatives, civil society organizations, educators, citizens, etc.) to respond in a responsible manner to the issues of our time (e.g., European Commission 2016; von Schomberg 2013). Consequently, a main implication when 
considering an RRI-aligned HE is that the current and future citizens and professionalswithin the broad R\&I ecosystem - need to be equipped with the capabilities to tackle grand challenges, to participate in RRI collaborative processes, and to contribute to the development of responsible societies.

However, initial scoping analyses reveal that, despite the relevance of RRI, there is a lack of knowledge about how to develop RRI-oriented HE curricula and about RRI capabilities that can be cultivated in students to be and to become responsible actors, researchers, and innovators in a complex world (McKenna 2016; Buckley et al. 2016; Mejlgaard et al. 2016). This paper attempts to address this gap and to identify elements in curricula design that can facilitate HE transition towards becoming more responsible and responsive. Those elements are distilled by bringing together scientific or technical knowledge with phronesis, a form of practical wisdom about what should be done in an ethical, moral, and political sense, in certain circumstances (Peters and Wals 2013). It should be emphasized that this study is exploratory and broad in nature; it makes a first step in understanding how to reorient HE to prepare students to engage in RRI. The analysis includes both Bachelor and Master levels of HE. Following the introduction, this paper includes five sections. First, it describes the approach of this study. Second, it discusses philosophical perspectives upon which this study is grounded as well as relevant insights and frameworks from the educational field. Third, it introduces a definition of RRI in higher education curricula and key elements for re-designing curricula in HE, including educational design principles and an RRI competence framework. Fourth, it provides policy considerations, followed by conclusions.

\section{Approach of the study}

This study is developed within the context of the "Enhancing Responsible Research and Innovation in Curricula of HE" (EnRRICH) project. This is a European Commission (EC) funded project which, as well as the authors, includes HE educators, scientists, nongovernmental and civil society representatives from Europe, and advisors from all over the world. This study approaches the task of enhancing RRI through HE, at both Bachelor and Master levels within a European context, not solely as a scientific and technical endeavor. Rather, it recognizes that this is a complex task that can be related to diverse educational, political, and practical contexts that requires ethical considerations and that can challenge routines in HE practices. Therefore, this study embraces epistemological pluralism (Miller et al. 2008), and it intentionally interweaves different ways of knowing and forms of knowledge. Especially, it attempts to integrate available scientific or technical knowledge with what Aristotle called phronesis.

In order to develop phronesis and incorporate scientific or technical knowledge, this study embraces an action research approach (e.g., Reason and Bradbury 2006). Action research is appropriate for this study because it is centered on producing practical knowledge rooted in a participatory worldview and on concrete actions for experimenting with change (Reason and Bradbury 2006 pp. 1-14). It thus implies the engagement of multiple and situated ways of knowing supported by the exploration of new ways of doing in the pursuit of practical outcomes. Over 18 months, the co-authors, alongside EnRRICH consortium partners, have engaged in an iterative and collaborative journey of reflection and action, supported by data collection and analysis through which they attempted to make sense and to foster RRI in and through $\mathrm{HE}$ at Bachelor and Master levels within their own institutions. 
A literature review was completed initially to gain insights about RRI from a scientific, philosophical, and ethical perspective (Tassone and Eppink 2016) and from a teaching and learning policy perspective (McKenna 2016; O'Mahony et al. 2016). This in turn informed the educational practices and pilots of the EnRRICH partners. The data collected and the experience gained throughout the project was interpreted through a process of thematic analysis to describe educational and pedagogical elements that can inform the uptake of RRI in HE. The thematic analysis is performed in various stages according to Boyatzis (1998). Firstly, samples from multiple sources have been selected and analyzed. Samples included: (a) text from Stilgoe et al. (2013, p. 1570-1573) and from Kupper et al. (2015, p. 19-38) providing scientific (the former) and practical (the latter) insights about relevant processes and capabilities in RRI contexts; (b) text from transcribed semi-structured interviews with educational stakeholders in 11 HEIs in Europe which were performed by EnRRICH partners to inform the pilots; (c) text describing RRI-related educational promising practices, i.e., 22 modules and programs, collected by EnRRICH partners and also used to inform the pilots (Living Knowledge 2016); (d) practices and pilots performed by EnRRICH partners attempting to foster RRIoriented education and pedagogy.

Secondly, the data was inductively encoded by two co-authors. In this approach, data from sample a), and from a subsample (a randomly selected part) of samples b) and c) was reduced first into an outline. Subsamples were identified in order to make the coding effort manageable and efficient given the large amount of data available (see Boyatzis $1998 \mathrm{pp}$. 60). Then, the information in the outline was organized into overarching themes which captured, within and across the data available, repeated patterns of meaning in the RRI-oriented educational elements. In order to ensure reliability, the coders worked independently of each other. The second coder applied the codes to the selected sample and subsample following the full encoding of the data by the first coder. Few divergences that were present were resolved through discussion. Additionally, a cross-validation was performed by applying the codes and generated themes to the remaining part of subsample b) and c). However, this cross-check did not bring new insights. Finally, the generated codes and themes were presented to EnRRICH partners, who analyzed them in light of the practical knowledge gained through their practices (sample d). Although no major modification in themes was required, this analysis contributed to a more nuanced understanding of the themes and led to the elaboration of a narrative supporting the description of the elements for educational design and pedagogy.

\section{A responsible research and innovation perspective}

\section{Understanding "responsibility" in research and innovation}

This section introduces the philosophical perspective taken when approaching RRI, and upon which we have grounded this study and the elaboration of elements for (re)-designing an RRIoriented curricula introduced in this paper. Saying that R\&I should be conducted with a sense of responsibility is something that not many would contest. RRI "intuitively feels right in sentiment, as an ideal or aspiration" (Owen et al. 2013, p. 27). While RRI may be easy to endorse, however, it may also raise questions about what being responsible entails within R\&I practices. The notion of responsibility can be approached differently depending on the viewpoint adopted (e.g., Grinbaum and Groves 2013). From a consequentialist viewpoint, responsibility is mainly interpreted as accountability or liability. Within this viewpoint, the 
researcher or innovator is meant to be accountable, and therefore responsible, for the outcomes of the practices undertaken. In this sense, responsibility implies the capability to use past and present knowledge to understand, and at best to predict, the impact of one's endeavors. The first issue here is that when the outcomes of one's endeavors are negative and do harm due to unforeseen events, and if the actor does not have full knowledge at the time of acting and his/ her intention is not harmful, then the actor cannot be considered culpable for negative unforeseen outcomes. A second issue arises from linking responsibility to individual's specific roles. For example, a researcher's responsibility can be reduced to "producing reliable knowledge." In this context, acting responsibly and ethically is about playing properly within the context of one's role and the rules of an established game. Notice that the morality and ethics underlying the game are not being questioned here. In other words, this conception of responsibility linked to a specific role does not include a broader morality and social responsibility towards humanity and the world (e.g., Grinbaum and Groves 2013) and the non-human and more-than-human world (Taylor and Hughes 2015; Reinertsen 2016).

This consequentialist notion of responsibility, still present in our society, emerged in classical times and evolved over time. It reflects a context where people live close to one another, their actions mainly impact on their immediate surroundings and rarely have irreversible impacts on the world at large and on the future (Owen et al. 2013, p. 36). But times have changed dramatically. Today we live in a globalized society characterized by an emerging complexity and severe grand sustainability challenges including climate change, toxification of water, air, soils, and human bodies, rising inequity, and displacement. The knowledge developed about these manifestations of global systemic dysfunction (Lotz-Sisitka et al. 2015) is contested, and while it answers certain questions, it also poses new queries and dilemma that add to our sense of uncertainty. Furthermore, the outcomes of R\&I practices do not evolve in a simple, linear fashion. Predicting with certainty possible impacts is difficult, if not impossible. And accountability for those impacts cannot be easily traced back. Additionally, R\&I endeavors involve multiple actors. Knowledge is thus co-produced. Actions and implications are systemic therefore responsibility is not an individual affair based uniquely on role responsibilities of selected actors. Rather, it is a shared and collective process.

It can be argued, as several scholars do (e.g., Adam and Groves 2011; Grinbaum and Groves 2013; Owen et al. 2013; Stilgoe et al. 2013), that the challenges of our time require a broader notion of responsibility, one that: aligns with the complex society of today, that acknowledges the importance of knowledge while accommodating its limitations, that allows for a deeper reflection about ways of doing and being, and also allows for the cultivation of social values and for socially and planetary relevant responses. From this more prospective viewpoint, the notion of responsibility includes new dimensions such as care and responsiveness, which are especially value-based and responsedriven (e.g., Noddings 2005; Grinbaum and Groves 2013; Jonas 1984; Pellizzoni 2004). The challenging conditions of our time call for human values that return us to our basic obligation to care for others and the earth, and to permeate our endeavors with that sense of care, within and beyond the specific role one plays in society at a given point in time. As suggested by Adam and Groves (2011, p. 17), care "can provide us with ethical resources that can guide us in the face of uncertainty." The implication is that a new paradigm is needed and new ways of operating and educating should be explored to enhance societal and planetary RRI efforts. 


\section{(Responsible) research and innovation through higher education}

This broad notion of responsibility is inspiring emergent work on RRI within various contexts. For example, RRI-related frameworks and insights are developed within the policy context (e.g., von Schomberg 2013), the science of technology context (e.g., Stilgoe et al. 2013), and the context of stakeholder practices in society (e.g., Kupper et al. 2015). Given the lack of knowledge about how to foster RRI within a HE curricula and pedagogy context, a crucial remaining question is related to what and how to teach future generations, and what are new approaches for (re-)designing academic curricula that allow for the embedding of a broad notion of responsibility. Before addressing this question through our study, it is important to point out that, without referring specifically to the notion of RRI, educational scholars have already proposed models and insights for the development of curricula that include a culture of responsibility (e.g., Barnett 2000; Boyer 1990; Brew 2003; Fanghanel and Cousin 2012; Fung 2017; Griffiths 2004; Wals et al. 2016). Those efforts argue that in the contemporary world, characterized by uncertainty, contestability, unpredictability, and by what Barnett (2000) defined as "supercomplexity," HE cannot confine itself only to transmitting and receiving bodies of predefined disciplinary knowledge, while curricular interventions cannot be seen merely as a technical endeavor. Rather, contemporary education and curricula should reflect the same cross-boundary, engaged, ethical, critical, and overall more responsible inquiry and innovation processes that researchers and stakeholders are called upon to undertake in our current society.

When it comes to the connection between research and education, as suggested by Healey (2005 p. 68), students are likely to gain most benefits from research when they are actively engaged in it, through for example inquiry-based processes. An expansive view of academic scholarship sees HE as being also engaged in scholarship of application described as the responsible application of knowledge to address significant problems (Boyer 1990 p. 21). Brew (2003) drawing from Boyer (1990) identifies the need to cultivate a sense of community and to develop communities of practice. Through such communities, students, academic, and other actors, become legitimate participants who build knowledge within a social context. When it comes to the connection between responsible innovation processes and education, Wals et al. (2016) suggest a praxis-oriented learning process that supports students to "walk the change." Central to this approach is a cyclical iterative journey of reflection and action: engaging learners in understanding why things are the way they are (current state), what keeps them from changing (maladaptive resilience), how things should be (more desirable state), what needs to be done to bring about change, trying out new ways of doing things, learning from the experience, and re-entering the cycle until a more desirable state has been reached. Last, it is crucial to refer to the work of Barnett (2007) which explicitly highlights the need to interweave knowledge (epistemology) and action (praxis) with being (ontology). It is through their being that students come into relationship with what they encounter, get to understand the world and to act in a certain way. Barnett (1995) highlights the need to identify a more adequate notion of competence to inform curricula, which not only focuses on gaining mastery within a discipline (academic competence) and on developing the know-how to perform well in the world of work (operational competence), but which is especially connected to the challenges of human life and grounded in a conception of humans contributing effectively to the life-world (life-world becoming).

Underpinning those studies is the recognition that, while each disciplinary and educational tradition has different ways to conceptualize R\&I which in turn impact curricula and pedagogy, 
deep changes are occurring in patterns of knowledge production (e.g., Gibbons et al. 1994). Nowadays, knowledge production appears to be less tied to disciplinary boundaries and to an exclusive focus on the academic setting and on cognitive learning. Rather, knowledge appears to be more socially distributed and linked to cross-boundary processes, to the site of application and to the engagement of various actors. In this sense, the divide between research efforts attributed to academia, and innovation efforts attributed to practitioners in society, is less evident. This new mode of knowledge production can come to life through responsible acts of innovation within particular contexts coupled with processes of collaborative inquiry and questioning of routines (e.g., Griffiths 2004 p. 716). We further argue that, in the context of our study, it would be even more appropriate to expand the term knowledge "production" into knowledge "co-creation and embodiment." The latter term emphasizes getting to know the world in a more relational way that allows for a deeper connection with "fellow humans" and also with "objects," "materials," and non-human beings, which may be a prerequisite for becoming more empathically responsible. Drawing from those insights and anchored in the broad notion of responsibility highlighted earlier, this study proposes some key elements for re-designing curricula that will be examined in the next section.

\section{Elements for (re-)designing a responsible research and innovation oriented higher education curricula}

\section{Working definition of RRI in higher education and elements for (re-)designing curricula}

Establishing a working definition of RRI in HE can provide educators with a foundation to develop curricula that can serve RRI purposes. By embracing a prospective notion of responsibility while including a consequentialist perspective, and by building on the relevant HE models and insights discussed above, this study proposes the following working definition of RRI in HE:

"Fostering RRI in higher education curricula is about equipping learners to care for the future by means of responsive stewardship of research and innovation practices that address the grand challenges of our time in a collaborative, ethical and sustainable way."

The educational fields within which this study has been performed and this definition has been developed include technical sciences and engineering, social sciences and humanities, and especially the interactions between them. In order to embed this definition and to advance RRI education in a HE context, this study proposes elements for re-designing curricula, including three educational design principles and an RRI competence framework (see Fig. 1). The educational design principles proposed are: education for society, education with society and educating whole persons. Those principles can be seen as building blocks to inspire development of programs and modules and

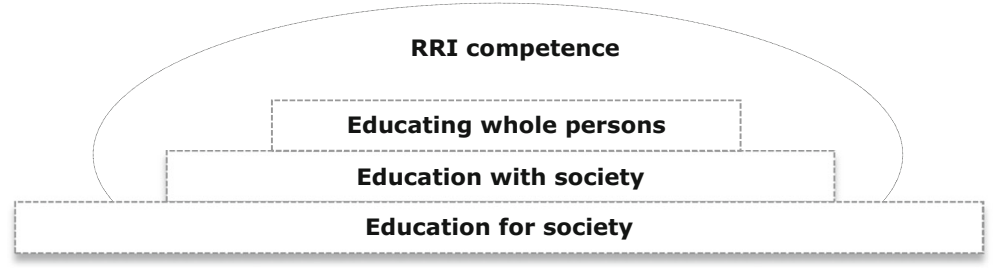

Fig. 1 Elements for a RRI-oriented higher education curricula design 
provide the conditions for creating a learning environment conducive to RRI learning and the development of an appropriate RRI competence. The RRI competence framework is comprised of a set of competencies characterized by an interplay of knowledge, skills and dispositions and including values.

\section{Educational design principles}

The first principle is "education for society." The grand societal challenges of Horizon 2020 (e.g., European Union 2016), of which RRI efforts are part, include addressing issues related to people, planet, and prosperity. Broadly speaking, tackling current societal issues is part of a universal agenda for sustainable development focusing on people, planet, and prosperity, and including also peace and partnership (e.g., United Nations 2015). Inevitably, as stated in the Lund Declaration (2015, p. 4) "we have to enable students to address societal challenges and accommodate their solutions for the benefit of society." Educating students to engage with real issues can provide them with the basis for responding to societal problems, for reflecting on what R\&I should contribute to, or at least for considering the wider societal and ecological contexts in which R\&I take place. In this sense, curricular development can be organized not only around subjects and disciplines, but around complex real-life challenges and contexts (e.g., Savin-Baden 2000). Problem-based learning and real-world learning (e.g., Brundiers et al. 2010; Savin-Baden 2000) are examples of pedagogical models that can help foster an education for society. However, given the complex and interconnected nature of real-life problems, it is crucial that pedagogical models engage students in cross-cutting forms of inquiry. While disciplinary specialism remains relevant, providing gateways in the curriculum for interdisciplinary inquiry can enable students to work towards cross-fertilization of disciplinary and also practical knowledge to address complex interconnected current challenges. This first principle connects well with other work within the educational field, for example with the scholarship of application suggested by Boyer (1990).

The second principle, which builds upon the first one, is "education with society." The Rome Declaration on RRI in Europe (2014, p. 1), building on the Lund Declaration and the Vilnius Declaration and linked to the EU Charter of Fundamental Rights, calls on all "stakeholders to work together for inclusive and sustainable solutions to our societal challenges." A main implication for an RRI-oriented HE curricula is that education needs to facilitate an interplay between academic and societal actors to prepare students for RRI endeavors. Problem-based learning and other pedagogies, involving students in educational practices that address real world problems, should favor a learning process of inquiry, knowledge co-creation, and innovation which takes place in reciprocal interaction between students and other actors. Overall, within curricula it is crucial to create critical and constructive dialogical spaces where students can discuss multiple perspectives, question viewpoints and routines, and produce socially robust knowledge and responses with scientists, governmental organizations, business, and civil society. Such spaces can become a source of collaborative, social, and trans-disciplinary learning, and have the potential to contribute to societal transformation and sustainability (e.g., Vilsmaier and Lang 2015; Wals and Peters 2018). In this process, transmissive forms of education can decrease progressively throughout the curricula, while more emancipatory forms of learning fostering interaction among students and with academic and societal actors can become more evident. Additionally, while students can get acquainted with participatory R\&I processes within the classroom through, for example, case studies and role plays, it is important that they also engage in authentic learning processes at the crossroads between the classroom and society, and collaboratively address concrete issues in society. This second principle of education with society connects well with the work of other 
educational scholars, for example with the "worldly" pedagogies by Fanghanel and Cousin (2012) and the communities of practice discussed by Brew (2003), highlighting the importance of fostering participation and critically engaging with differences in order to address global questions.

The third principle, which builds upon the first and second ones, is "educating whole persons." In order to further embed a sense of responsibility through education, learning processes that support the cultivation of (new) ways of knowing, being, and doing are needed. RRI can be facilitated through the inclusion and juncture of, at least, three learning domains, namely cognitive, affective, and psycho-motor learning domains (e.g., Sipos et al. 2008). Cognitive learning, or "learning to know," is needed in order to understand and research the complex issues of our time, to navigate uncertainties, to experiment with, and to evaluate new ways of addressing issues in society. Learning to know, as we describe it here, does not exclude knowledge transfer but it especially allows for deeper or transformative learning through which new, more inclusive and discriminating perspectives can open up (e.g., Mezirow et al. 2009) and new forms of disruptive thinking can be developed (e.g., LotzSisitka et al. 2015). Additionally, learning about RRI includes learning within the affective domain, or "learning to be." Affective capacities are required because collaborating, cultivating social attitudes and values, and nurturing a sense of care and stewardship are not merely intellectual exercises, but a way of being and of relating to ourselves, to others, and to the planet. Furthermore, learning about RRI includes the psycho-motor domain, or "learning to do." This relates to our behavior, to the tangible and physical expression of our capacities, for example through multi-perspective communication endeavors. Learning to do, as intended here, relates also to acts of care or disruptive forms of agency and human actions that can be undertaken in order to question, resist, and bring change to current states of affairs and contribute to societal transitions (e.g., Lotz-Sisitka et al. 2015). Although those three learning domains are presented here as distinct from one another, in practice those three learning domains need to be interwoven and challenged simultaneously (e.g., Barnett 2007), for example through experiential or praxis-oriented learning processes that support students to learn while "walking the change" as proposed by Wals et al. 2016.

As argued elsewhere (e.g., Fien 1997; Noddings 2005), equipping learners to care-which is a leading element in the proposed definition of RRI in HE in this paper-implies an educational process that involves the cultivation of affective capacities, conceptual understanding, and the skills to act and to respond to a need, a problem, a challenge, etc. By exposing students to reallife problems, by involving them in critical reflection, creative expression, collaborative interactions and ethical considerations, as already suggested through the previous principles, those various learning domains can be put into practice through HE. This can allow turning the notion of care and more broadly of responsibility within R\&I efforts, into a living educational process.

\section{RRI students' competencies to be embedded in curricula}

After suggesting educational design principles, we propose a RRI competence framework to inform the development of curricula enabling students to participate in RRI processes (see Fig. 2, and text box 1). The notion of competence has been explored by various authors with a focus on addressing societal sustainability challenges (e.g., Barth et al. 2007; Rieckman 2012; Wals 2010a; Wiek et al. 2011). In this study, the RRI competence is defined as an overarching and multi-dimensional competence that can be conducive to RRI. The RRI competence comprises a set of competencies. Each of those competencies represents a dynamic interplay between knowledge, skills, and dispositions 
connected to values, which call for learning to know, learning to do, and learning to be as discussed above. Those competencies emerge in interaction with others and the situation and/or environment in which activities take place (Wals 2010b, p. 149). They are articulated across four RRI dimensions, namely anticipation, reflexivity, inclusiveness, and responsiveness. Those dimensions are aligned to those introduced by Stilgoe et al. (2013) and relate to those described by Kupper et al. (2015). While each competence stands within a certain dimension, the competencies and dimensions are interlinked. Hence, the lines between them are blurred. The dynamic interactions between competencies and dimensions help create a multi-dimensional RRI competence which can enable RRI as intended in the definition and through the design elements already presented.

Orientated towards addressing societal challenges, this competence framework resonates with Barnett's (1995) conception of "life-world becoming," encouraging the unfolding of higher order goals for both the individual and society. Furthermore, the framework recognizes that RRI is a complex matter that can be related to diverse contexts, subject areas, and actors. In the attempt to embrace this complexity and diversity, the framework is context independent. It is also not exhaustive, nor prescriptive. Rather, the RRI competence framework is meant as a heuristic that can inspire the (re-)design of programs and modules in different ways. For example, relevant single RRI competencies can inform the development of single modules within a program, while a combination of those competencies can guide the development of other single modules within the same program; or, while conveying basic disciplinary knowledge and research skills in the first phase of a study program, the framework proposed here could inform the second phase of the program; or, the framework can inspire the development of modules that provide the conditions for engaging with multiple RRI competencies which students themselves can choose based on their learning needs, thus fostering self-directed learning.

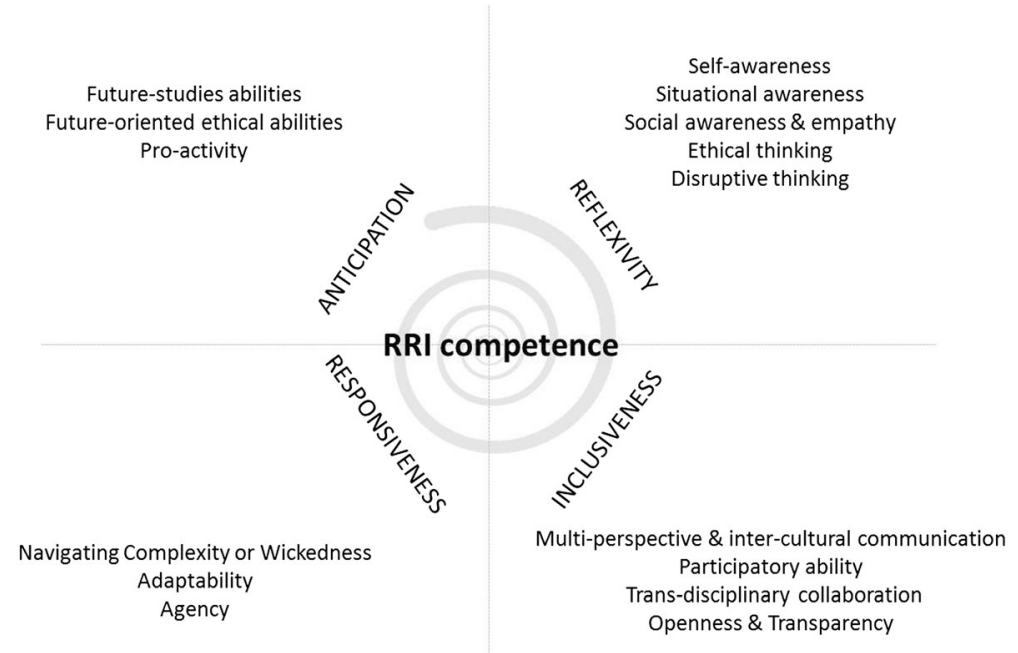

Fig. 2 The RRI competence framework 
Text box 1 Description of RRI relevant competencies within each dimension

\section{Dimension: ANTICIPATION}

Including competencies in anticipating societal challenges and future implications through R\&I practices

- Future-studies capabilities: understand, engage with, and appreciate concepts, methods, and applications for exploring and managing possible futures

- Future-oriented ethical capabilities: understand, engage with, and appreciate ethical principles and their applications when considering possible futures and anticipatory endeavors

- Pro-activity: understand, engage with, and appreciate a pro-active mind-set and action

Dimension: REFLEXIVITY

Including competencies in reflecting about contexts, ways of knowing, ways of doing, and ways of being related to societal challenges and to R\&I practices

- Self-awareness: understand, engage with, and appreciate reflexivity and self-awareness about own dispositions, assumptions, norms, and values

- Situational awareness: understand, engage with, and appreciate awareness development concerning norms, needs, and wants in a specific situation

- Social awareness and empathy: understand, engage with, and appreciate the feelings of another, and awareness development concerning social needs

- Ethical thinking: understand, engage with, and appreciate ethical reflections and ethical assessment of perspectives, endeavors, and outputs

- Disruptive thinking: understand, engage with, and appreciate disruptive ways of thinking that challenge current status-quo and go beyond conventional ways of knowing and doing

Dimension: INCLUSIVENESS

Including competencies in involving, communicating with, collaborating with diverse stakeholders and the wider public to address societal challenges through R\&I practices

- Multi-perspective and inter-cultural communication: understand, engage with, and appreciate communication strategies that include multiple perspectives, frames of reference, and cultures

- Participatory ability: understand, engage with, and appreciate participatory decision-making processes that includes voices of diverse stakeholders, also the wider public and silent voices

- Trans-disciplinary collaboration: understand, engage with, and appreciate collaborative and bridge-making efforts across disciplines, actors, and contexts

- Openness and transparency: understand, engage with, and appreciate the process of sharing information about findings, processes, and practices while being mindful of possible restrictions in sharing information (e.g., intellectual property rights, considerations around sensitive data)

\section{Dimension: RESPONSIVENESS}

Including competencies in coping with and responding to societal challenges and to emergent (social) needs, values, norms, perspectives, and knowledge through R\&I practices

- Navigating complexity or wickedness: understand, engage with, and appreciate complexities, uncertainties, and ambiguities and manage a possible sense of paralysis or of being overwhelmed

- Adaptability: understand, engage with, and appreciate flexible and adaptable design and practices to cope with emergent challenges and changes in society, revise views, and adjust the course of action

- Agency: understand, engage with, and appreciate purposive actions through which one can initiate or contribute to change while being mindful of supportive or less supportive factors

\section{Policy considerations}

One of the challenges to equip HE students to effectively participate in RRI is the creation of an encouraging policy environment. Some European policies incentivise an RRI approach, however these largely relate to the European Research Area and to efforts to bridge science and society (e.g., European Commission 2016). When it comes to European HE teaching and learning policies, a review undertaken as part of EnRRICH (McKenna 2016) suggests that RRI is barely referenced in European HE policy and few efforts are being made to facilitate a transition to HE curricula which incorporate RRI elements. European HE teaching and learning policies focus on strengthening the potential of HE to contribute to Europe's prosperity and growth, more recently sustainable growth, overall placing less emphasis on 
socio-ecological aspects related to the well-being of people and planet which are crucial in fostering an education for society. For example, HEIs are considered key partners in supporting the EU 2020 strategy to drive economic sustainable growth, and on delivering workers for the European economy (e.g., European Commission 2010, 2011).

Collaborations between $\mathrm{HE}$ and other societal actors, in pursuit of excellence and regional development, are encouraged by the EU (e.g., European Commission 2011) and can thus favor an interplay between academia and society and overall an education with society. An emphasis has been placed on synergies between the scientific, educational, and business world, i.e., the "knowledge triangle" (e.g., European Commission 2011), with less mention of CSOs, the wider public and other stakeholders. However, there is a growing recognition of the need to orient HEIs towards becoming "civic-minded learning communities connected to their communities" (European Commission 2017, p.7). The High Level Group on Modernization of Higher Education acknowledges that Europe's graduates require an education that promotes inter- and trans-disciplinarity and that enables students to engage articulately as committed, active, global citizens as well as actors in the ethical and sustainable development of our societies, but also recognizes that European HE systems do not routinely offer this kind of teaching experience (European Commission 2013). In spite of that, the emerging emphasis on the role of education in fostering inclusion and equality, active citizenship, and democratic competencies (e.g., Council of Europe 2016; European Commission 2017 p. 12), also in response to incidences of violent extremism at the start of 2015 (e.g., European Union 2015), may offer an opportunity for further considering the importance of educating whole persons and for the development of competencies that can serve RRI purposes and foster care and responsiveness towards societal challenges.

While European HE policies can be influential in terms of guiding curricula, member states interpret and implement these policies in line with their national contexts and needs. National policies are further distilled by HEIs to reflect their strategic foci and pedagogical traditions. A review of national and institutional policies by EnRRICH partners (O'Mahony et al. 2016) uncovered various policies that reference the need to make education relevant for society and the need to connect with societal actors in line with an education with society (e.g., Higher Education Authority 2013, Nederlands-Vlaamse Accreditatie Organisatie 2015, and Higher Education Funding Council for England 2016), though still with a stronger focus on meeting the needs of the labor market and enhancing global and local prosperity. There was little evidence of incentives in academic staff recruitment and promotion criteria to support the embedding of RRI in curricula. A main focus in academia is on rankings, productivity, income generation, and knowledge commercialization. Staff can be requested to demonstrate engagement with societal issues though this is more related to research activities and contribution to societal debates and less so to educational activities. Lack of support at the level of institutions as well as lack of incentives for the individuals attempting to bring RRI pedagogy and teaching into HE remain important challenges (e.g., Mejlgaard et al. 2016).

There are changes afoot however. For example, the University of Vechta (2016) which has developed its own competence framework for teaching and learning identifies public engagement as a key outcome of education. Queen's University Belfast (2016) emphasizes global citizenship and awareness of social, ethical, and political responsibilities in a complex global world. Wageningen University (2017) highlights the need for equipping students to contribute to sustainable solutions and to take on their social, personal, and ethical responsibilities. Those examples appear promising for fostering a RRI-oriented education as illustrated in this study. Models exist to translate these types of policies into practice. For example, within the field of 
sustainability education, efforts are made to provide challenge-based, cross-boundary, and transformative educational experiences (e.g., Rowe 2007). The "Science Shop" model can enhance collaborative research practices and can link HE students and staff with societal actors, specifically with underserved CSOs, to address questions and issues of relevance for those organizations and society (www.livingknowledge.org). Other models also exist, e.g., Living Labs and StartHubs. HE-related networks are also emerging, committed to enhancing collaborative educational R\&I practices connected to real challenges, e.g., Campus Compact, Commonwealth Universities Extension and Engagement Network, Global Alliance of Community Engaged Research, Global Universities Network for Innovation, Imagining America, PASCAL International Observatory, and the Living Knowledge Network. Although a comparative analysis of effectiveness, similarities and differences among all those initiatives goes beyond the purpose of this study, we consider those attempts as promising for supporting the renewal of $\mathrm{HE}$ in the direction discussed in this paper.

\section{Conclusions}

The increasing need to respond to complex grand sustainability challenges and the increasing relevance of the RRI policy agenda call for new and more responsible ways of operating, researching, and innovating that enable society to respond to those challenges. This paper has attempted to make a first step towards answering this call by exploring how to reorient $\mathrm{HE}$ curricula to prepare students to navigate societal challenges and to engage in RRI. Taking an RRI perspective, and based on phronesis next to scientific knowledge, this paper suggests a working definition of RRI in HE, three educational design principles, and a RRI competence framework that can inspire the development of a RRI-oriented curricula, relevant for Bachelor and Master students. As the experience of the EnRRICH project indicates, HEIs are able to create spaces where it is possible to act as part of the public sphere and realize public and social values alongside building understanding and capacities about RRI.

However, this paper also suggests that contemporary HE teaching and learning policies and strategies, especially promoting neoliberal agendas and marketized practices, need to adopt a more responsible ethos in order to support the RRI policy call, the embedding of a RRIoriented curricula, and the efforts of committed educators and emerging networks attempting to foster new and more responsible forms of teaching and learning.

It is important for HE to focus on being relevant (e.g., connecting to real-world issues through inquiry processes) and responsive (e.g., keeping up with changes), but it is especially important to focus on being reflexive (e.g., considering and questioning the underlying normalized assumptions and values of one's endeavors) and to foster an ethics of care (e.g., considering the perspectives and needs of others and the ethical implications of those endeavors). Through RRI, by formally adding "responsible" to traditional neoliberal research and innovation, European policy is providing space for critical reflection about what it means to be responsible actors, researchers, and innovators in the midst of 21 st century challenges. Such space is critical in times of global systemic dysfunction, and can further encourage HE to rethink its public role, to respond to the challenges of our time, and to reclaim its potential to transform society with people and planet in mind.

Acknowledgements The authors are grateful to the EnRRICH consortium partners for their crucial contribution in co-developing the knowledge shared in this paper, and to two anonymous reviewers of this paper for their insightful comments. 
Open Access This article is distributed under the terms of the Creative Commons Attribution 4.0 International License (http://creativecommons.org/licenses/by/4.0/), which permits unrestricted use, distribution, and reproduction in any medium, provided you give appropriate credit to the original author(s) and the source, provide a link to the Creative Commons license, and indicate if changes were made.

\section{References}

Adam, B., \& Groves, G. (2011). Futures tended: care and future-oriented responsibility. Bulletin of science. Technology \& Society, 31, 17-27.

Barnett, R. (1995). The limits of competence: knowledge, higher education and society. Berkshire: McGraw-Hill/ Open University Press.

Barnett, R. (2000). University knowledge in an age of supercomplexity. Higher Education, 40(4), 409-422.

Barnett, R. (2007). A will to learn: being a student in an age of uncertainty. Berkshire: McGraw-Hill/Open University Press.

Barth, M., Godemann, J., Rieckman, M., \& Stoltenberg, U. (2007). Developing key competences for sustainable development in higher education. International Journal Sustainable Higher Education, 8(4), 416-430.

Boyatzis, R. E. (1998). Transforming qualitative information. Thematic analysis and code development. Cleveland: Sage.

Boyer, E. L. (1990). Scholarship reconsidered: priorities of the professoriate. Princeton: Carnegie Foundation for the Advancement of Teaching.

Brew, A. (2003). Teaching and research: new relationships and their implications for inquiry-based teaching and learning in higher education. Higher Education Research and Development, 22(1), 3-18.

Brito, L., and Stafford-Smith, M. (2012). State of the Planet Declaration. Planet Under Pressure: New Knowledge Towards Solutions conference, London, 26-29 March 2012. http://www.igbp.net/download/18.6 b007aff13cb59eff6411bbc/1376383161076/SotP_declaration-A5-for_web.pdf. Accessed 9 September 2017.

Brundiers, K., Wiek, A., \& Redman, C. L. (2010). Real-world learning opportunities in sustainability: from classroom into the real world. International Journal of Sustainability in Higher Education, 11(4), 308-324.

Buckley, N., Tassone, V.C. and Eppink, H.J. (2016). Initial Review of Responsible Research and Innovation aspects in higher education curricula in Europe: consultation and analysis of needs. Deliverable 2.1. EnRRICH project. Horizon 2020.

Council of Europe (2016). Competencies for democratic culture. Living together as equals in culturally diverse democratic societies. Strasbourg: Council of Europe.

Crutzen, P. J. (2002). Geology of mankind. Nature, 415(6867), 23-23.

European Commission (2010). A Strategy for Smart, Sustainable and Inclusive Growth. COM (2010) 2020. Brussels: European Commission.

European Commission. (2011). Supporting growth and jobs: An agenda for the modernisation of Europe's higher education systems. Luxembourg: Publications Office of the European Union.

European Commission (2013). Report to the European Commission on improving the quality of teaching and learning in Europe's higher education institutions. Luxembourg: Publications Office of the European Union.

European Commission (2016). Research and innovation-science with and for society. https://ec.europa. eu/research/swafs/index.cfm?pg=about. Accessed 9 Sept 2017.

European Commission (2017). On a renewed EU agenda for higher education. Brussels: European Commission. https://ec.europa.eu/education/sites/education/files/he-com-2017-247_en.pdf. Accessed 9 Sept 2017.

European Union (2015). Draft joint report of the Council and the Commission on the implementation of the strategic framework for European cooperation in education and training (ET2020). http://ec.europa. eu/education/documents/et-2020-draft-joint-report-408-2015_en.pdf. Accessed 1 Sept 2017.

European Union (2016). The EU Framework Programme for Research and Innovation, Horizon 2020. https://ec. europa.eu/programmes/horizon2020/en/h2020-section/societal-challenges. Accessed May 2016.

Fanghanel, J., \& Cousin, G. (2012). Worldly' pedagogy: a way of conceptualising teaching towards global citizenship. Teaching in Higher Education, 17(1), 39-50.

Fien, J. (1997). Learning to care: a focus for values in health and environmental education. Health Education Research, 12(4), 437-447.

Fung, D. (2017). A connected curriculum for higher education. London: UCL.

Gibbons, M. (1999). Science's new social contract with society. Nature, 402, C81-C84.

Gibbons, M., Limoges, C., Nowotny, H, Schwartzman, S., Scott, P. and Trow, M. (1994). The new production of knowledge: The dynamics of science and research in contemporary societies. London: Sage Publications.

Gibson, K., Bird Rose, D., \& Fincher, R. (Eds.). (2015). Manifesto for living in the Anthropocene. Brooklyn: Punctum books. 
Griffiths, R. (2004). Knowledge production and the research-teaching nexus: the case of the built environment disciplines. Studies in Higher Education, 29(6), 709-726.

Grinbaum, A., \& Groves, C. (2013). What is "responsible" about responsible innovation? Understanding the ethical issues. In R. Owen, J. Bessant, \& M. Heintz (Eds.), Responsible innovation: managing the responsible emergence of science and innovation in society (pp. 119-142). London: Wiley.

Higher Education Authority (2013). Guidelines for completion of mission-based performance compacts. Dublin: Higher Education Authority. https://brianmlucey.files.wordpress.com/2013/08/2-guidelines-for-completion-ofcompact.pdf. Accessed 18 September 2017.

Healey, M. (2005). Linking research and teaching: exploring disciplinary spaces and the role of inquiry-based learning. In R. Barnett (Ed.), Reshaping the university: new relationships between research and teaching (pp. 30-42). Maidenhead: McGraw-Hill/Open University Press.

Higher Education Funding Council for England (2016). Policy guide: Research Excellence Framework impact. www.hefce.ac.uk/rsrch/REFimpact/. Accessed 9 Sept 2017.

Jonas, H. (1984). The imperative of responsibility. In search of an ethics for the technological age. Chicago: University of Chicago Press.

Kates, R. W., Clark, W. C., Corell, R., Hall, J. M., Jaeger, C. C., Lowe, I., McCarthy, H. J., et al. (2001). Sustainability science. Science, 292(5517), 641-642.

Kupper, F., Klaassen, P., Rijnen, M., Vermeulen, S., Woertman, R., Broerse, J. (2015). A catalogue of good RRI practices. Deliverable 1.4, RRI tools project. EU Horizon 2020.

Living Knowledge (2016). RRI promising practices and case studies. http://www.livingknowledge. org/projects/enrrich/enrrich-resources/. Accessed 9 Sept 2017.

Lotz-Sisitka, H., Wals, A. E. J., Kronlid, D., \& McGarry, D. (2015). Transformative, transgressive social learning: rethinking higher education pedagogy in times of systemic global dysfunction. Current Opinion in Environmental Sustainability, 16, 73-80.

McKenna, E. (2016). Deliverable 5.1 Summary Report on Policy for Rewarding Responsible Research and Innovation through academic curricula in Higher Education. Deliverable 5.1, EnRRICH project. EU Horizon 2020.

Mejlgaard, N., Buljan I., Elías, S.N., i Giralt, M.C., Griessler, E., Hansen, L.S., Lang, A., Marušić, A., de la Poza, G.R., Strand, R., \& Wuketich, M. (2016). State of the art review. Higher Education Institutions \& Responsible Research and Innovation. Deliverable 2.2, HEIRRI project. EU Horizon 2020.

Mezirow, J., Taylor, E., et al. (Eds.). (2009). Transformative learning in practice: Insights from community, workplace and higher education. San Francisco: Jossey-Bass.

Miller, T. R., Baird, T. D., Littlefield, C. M., Kofinas, G., Chapin, F. S. I. I. I., \& Redman, C. L. (2008). Epistemological pluralism: reorganizing interdisciplinary research. Ecology and Society, 13(2), 46.

Noddings, N. (2005). The challenge to care in schools (2nd ed.). New York: Teachers College Press.

Nederlands-Vlaamse Accreditatie Organisatie (2015). Quality Code Flanders 2015-2017. Brussels: NVAO. www. nvao.com/procedures/quality-code-flanders-2015-2017. Accessed 9 Sept 2017.

O'Mahony, C, Hally, R. \& Burns, K. (2016). Institutional, national and international policies that encourage the embedding of RRI in Higher Education curricula. Milestone 13, EnRRICH project. EU Horizon 2020 .

Owen, R., Stilgoe, J., Macnaghten, P., Gorman, M., Fisher, E., \& Guston, D. (2013). A framework of responsible innovation. In R. Owen, J. Bessant, \& M. Heintz (Eds.), Responsible innovation: managing the responsible emergence of science and innovation in society (pp. 27-50). London: Wiley.

Pellizzoni, L. (2004). Responsibility and environmental governance. Environmental Politics, 13, 541-565.

Peters, S., \& Wals, A. E. J. (2013). Learning and knowing in pursuit of sustainability: concepts and tools for trans-disciplinary environmental research. In M. Krasny \& J. Dillon (Eds.), Trading zones in environmental education: creating transdisciplinary dialogue (pp. 79-104). New York: Peter Lang.

Queen's University Belfast (2016). Education strategy 2016-2021. Internal strategic document. Belfast: Queen's University Belfast.

Reason, P., \& Bradbury, H. (2006). Handbook of action research. London: Sage publications.

Reinertsen, A. (2016). Becoming earth: a post human turn in educational discourse collapsing nature/culture divides. Rotterdam: Sense Publishers.

Rieckman, R. (2012). Future-oriented higher education: Which key competencies should be fostered through university teaching and learning? Futures. Special Issue: University. Learning, 44(2), 127-135.

Rome Declaration on Responsible Research and Innovation (2014). Presidency of the Council of the European Union. https://ec.europa.eu/research/swafs/pdf/rome_declaration_RRI_final_21_November.pdf. Accessed 9 Sept 2017.

Rowe, D. (2007). Education for a sustainable future. Science, 317(5836), 323-324.

Savin-Baden, M. (2000). Problem-based learning in higher education: untold stories. Buckingham: Society for Research in Higher Education. 
Sipos, Y., Battisti, B., \& Grimm, K. (2008). Achieving transformative sustainability learning: engaging head, hands and heart. International Journal of Sustainability in Higher Education, 9(1), 68-86.

Steffen, W., et al. (2011). The Anthropocene: from global change to planetary stewardship. Ambio, 40, 739-761.

Sterling, S., Maxey, L., \& Luna, H. (Eds.). (2013). The sustainable university: progress and prospects. Abingdon: Routledge, Earthscan.

Stilgoe, J., Owen, R., \& Macnagthen, P. (2013). Developing a framework for responsible innovation. Research Policy, 42, 1568-1580.

Swedish Research Council (2015). Background paper to the Lund Declaration 2015. Lund Revisited. Tackling Societal Challenges conference, Lund, Sweden, 3-4 December 2015. https://www.vr.se/download/18.34 f000731515db13770f067b/1449066274419/Background+paper+to+the+Lund+Declaration+2015_final.pdf. Accessed 9 Sept 2017.

Tassone, V. \& Eppink H. (2016). Responsible Research and Innovation in higher education. A scoping document. Milestone 5, EnRRICH project. EU Horizon 2020.

Taylor, C., \& Hughes, C. (2015). Posthuman research practices in education. London: Palgrave Macmillan.

The Royal Society (2012). People and the planet. The Royal Society Science Policy Centre Report 01/12, London: Royal Society Policy Centre.

United Nations (2015). Transforming our world. The 2030 agenda for sustainable development. New York: UN General Assembly.

University of Vechta (2016). Kompetenzrahmen der Universität Vechta. Retrieved from www.uni-vechta. de/einrichtungen-von-a-z/invectra/hochschuldidaktik/kompetenzrahmen/. Accessed 9 Sept 2017.

Vilsmaier, U., \& Lang, D. J. (2015). Making the difference by marking the difference: constituting in-between spaces for sustainability learning. Current Opinion in Environmental Sustainability, 16, 51-55.

von Schomberg, R. (2013). A vision of responsible innovation. In R. Owen, J. Bessant, \& M. Heintz (Eds.), Responsible innovation: managing the responsible emergence of science and innovation in society (pp. 5174). London: Wiley.

Wageningen University (2017). Vision for Education 2017, Wageningen University Education, the next step. Wageningen University and Research.

Wals, A. E. J. (2010a). Mirroring, Gestaltswitching and transformative social learning: stepping stones for developing sustainability competence. International Journal of Sustainability in Higher Education, 1(4), $380-390$.

Wals, A. E. J. (2010b). Between knowing what is right and knowing that is it wrong to tell others what is right: on relativism, uncertainty and democracy in environmental and sustainability education. Environmental Education Research, 16(1), 143-151.

Wals, A. E. J., \& Peters, M. A. (2018). Flowers of resistance. Citizen science, ecological democracy and the transgressive education paradigm. In A. König (Ed.), Sustainability science. London: Taylor and Francis.

Wals, A. E. J., Tassone, V. C., Hampson, G. P., \& Reams, J. (2016). Learning for walking the change: eco-social innovation through sustainability-oriented higher education. In M. Barth, G. Michelsen, M. Rieckmann, \& I. Thomas (Eds.), Routledge handbook of higher education for sustainable development (pp. 25-39). London: Routledge.

Wiek, A., Withycombe, L., \& Redman, C. L. (2011). Key competencies in sustainability: a reference framework for academic program development. Sustainability Science, 6(2), 203-218. 